\title{
Concreto estrutural com britas de Tomar do Geru no Estado de Sergipe
}

Structural concrete with coarse aggregate from Tomar do Geru district in Sergipe State

\author{
L. A. C. Viana Neto; A. T. C. Sales; M. L. S. Rosa \\ Deparatamento de Engenharia Civil, Universidade Federal de Sergipe, 49100-000,Aracaju-Sergipe, Brasil \\ angelasales19@gmail.com
}

(Recebido em 10 de junho de 2015; aceito em 29 de outubro de 2015)

\begin{abstract}
Agregados são insumos básicos para os concretos, que têm sua qualidade dependente, dentre outros fatores, de bons índices tecnológicos de seus componentes. Os agregados graúdos influenciam na resistência mecânica e durabilidade dos concretos. O objetivo do presente trabalho foi verificar a viabilidade da utilização de britas de duas jazidas do município de Tomar do Geru, Sergipe, chamadas de GR-504 e GR-505, na produção de concretos estruturais. Foram feitos ensaios de resistência à compressão axial, módulo de elasticidade à compressão e tração por compressão diametral, comparando os concretos feitos com essas britas, com um concreto de referência, moldado com brita frequentemente usada em concretos estruturais. Ao comparar o concreto de referência, com aqueles que continham as britas estudadas, observaram-se reduções de resistência à compressão, da ordem de 2,6\% e 11,9\%, respectivamente, para as britas GR-504 e GR-505. O módulo de elasticidade teve reduções de 9,3\% e 14,8\%, respectivamente, para as britas GR-504 e GR-505, da mesma forma que a resistência à tração indireta, com reduções de $1,4 \%$ e $6,1 \%$, respectivamente. Porém essas reduções foram consideradas aceitáveis, pois todos os três concretos, moldados com britas comercial, GR-504 e GR-505, alcançaram valores de resistência à compressão superiores à resistência característica à compressão $\left(\mathrm{f}_{\mathrm{ck}}\right)$ fixada na dosagem do concreto. Foi possível concluir que as britas das duas jazidas de Tomar do Geru podem produzir concretos que, em termos de desempenho mecânico, podem ser aplicados com finalidades estruturais.
\end{abstract}

Palavras-chave: Tomar do Geru, agregado britado, ensaios comparativos

Aggregates are basic inputs for the concrete and the mixture quality depends on good technological indexes of its components. The coarse aggregates influence the strength and durability of concrete. The objective of this study was to investigate the feasibility of using coarse aggregate from two fields in Tomar do Geru district, state of Sergipe, in structural concrete. These fields are named GR-504 and GR505. Mechanical tests were developed to measure compressive strength, elastic modulus under compression and traction by diametrical compression by comparing the concrete made with these aggregates with reference mixture with commercial coarse aggregate commonly used in structural concrete. When comparing with the reference concrete, the concretes containing those studied aggregate showed reductions in compressive strength of $2.6 \%$ and $11.9 \%$, respectively, when coarse aggregates from fields GR-504 and GR-505 were used. The modulus of elasticity was reduced by $9.3 \%$ and $14.8 \%$ for aggregates from GR-504 and GR-505. Indirect tensile strength showed reductions of $1.4 \%$ and $6,1 \%$, respectively. However, these reductions were considered acceptable, because all types of concretes reached compressive strength values higher than the characteristic compressive strength $\left(\mathrm{f}_{\mathrm{ck}}\right)$ related to the design of concretes. It was concluded that these coarse aggregates, from the two fields in Tomar do Geru, could produce concretes that, in terms of mechanical performance, are adequate for structural purposes Keywords:Tomar do Geru, crushed aggregate, comparative tests

\section{INTRODUÇÃO}

O município de Tomar do Geru está localizado no extremo sul do estado de Sergipe e ocupa uma área de $304,903 \mathrm{~km}^{2}$. A população foi estimada, em 2014, em 13.196 habitantes [1].A mineração é destaque nas atividades do município. Um dos litótipos do complexo gnáissicomigmatítico, os ortognaisses migmatíticos de composição granodiorítica, são intensamente explorados em pedreiras nas circunvizinhanças da cidade de Tomar do Geru, onde são produzidas pedras de talhe (paralelepípedos, meios-fios etc.) e de alicerce/alvenaria, sendo um 
dos polos produtores de pedra de alvenaria e de talhe, atendendo a $30 \%$ da demanda do estado de Sergipe. A Figura 1 mostra uma área de exploração [2].

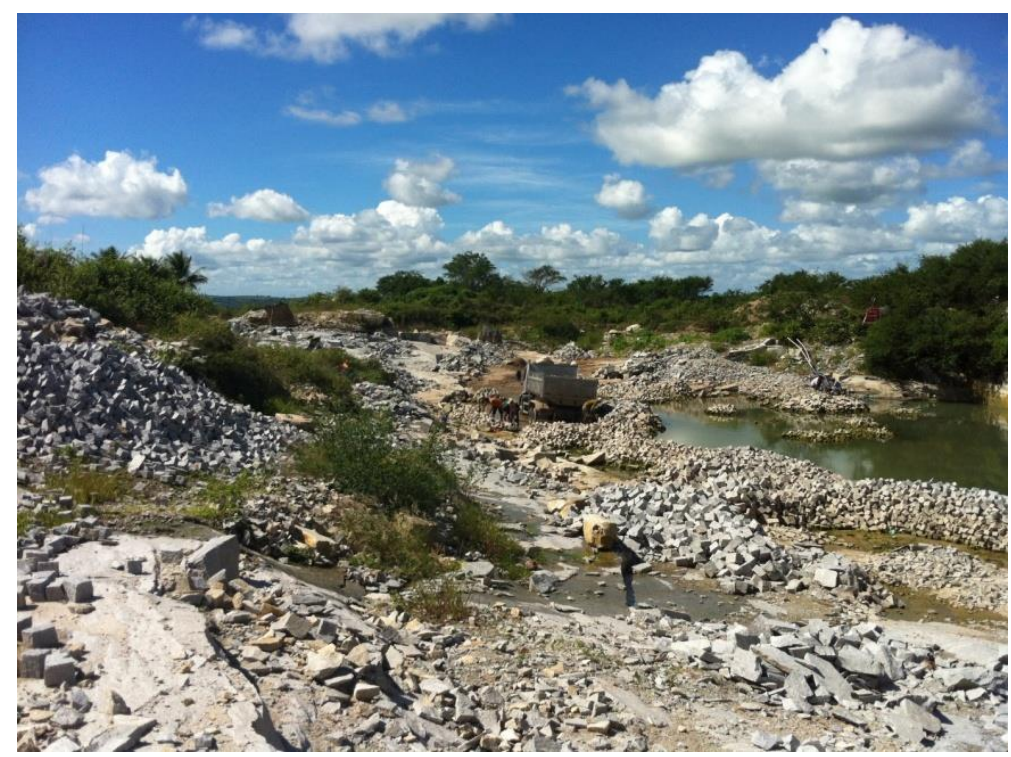

Figura 1: Produção mineral em Tomar do Geru

O presente trabalho originou-se de uma demanda do Ministério Público Federal em Sergipe, visando à melhoria da produção da Cooperativa COOPERPEDRAS, através da orientação aos produtores de artefatos de pedra do município, quanto à possibilidade de passarem a produzir e comercializar britas, que são geradas como sub-produto. Assim, o presente estudo teve como objetivo geral analisar as propriedades mecânicas de concretos estruturais produzidos com britas de duas jazidas do município, Cardoso 2, identificada como jazida 504, e Laje Grande, identificada como jazida 505, visando à utilização como agregado graúdo para concreto estrutural.

Segundo Ferreira e Oliveira (2009) [3], as características que tornam os agregados fundamentais para o setor da construção civil são: (i) menor preço unitário dentre todos os minerais industriais; (ii) Grande número de ocorrências dos diversos tipos de minerais; (iii) pesquisa geológica simples, baixa demanda por tecnologia (lavagem, classificação e/ou moagem).

Porém, a demanda de agregados para construção é intensificada e restringida ou impedida, simultaneamente. Este fato se deve à acelerada urbanização notada em grande parte das cidades, que fomentam fornecimento de agregados para continuar seu crescimento desenfreado, e aos problemas relacionados à ocupação do terreno, como o inadequado planejamento, problemas ambientais, zoneamentos restritivos e usos competitivos do solo, que comprometem o funcionamento das empresas mineradoras, levando-as ao fechamento ou migração para áreas remotas[4,5,6]. Assim, de forma a manter o atendimento à demanda mineral na construção, as tendências apontam para o aproveitamento dos resíduos de produção dos agregados e da construção civil.

Agregados graúdos obtidos por britagem da rocha têm uso em larga escala na construção civil, compondo concretos, misturas betuminosas, lastros de ferrovias etc. Segundo Campos et al. (2007) [7], os agregados são insumos de grande importância para o desenvolvimento socioeconômico de um país, constituindo-se num dos bens minerais mais consumidos no mundo. Apesar da importância desses materiais, essa atividade mineradora é, frequentemente, exercida sem controle, tanto na qualidade do produto final, quanto no que tange à legislação ambiental e mineral. As britas originárias das rochas, ao contrário de outros materiais como aço e madeira, dispensam tratamento prévio de preservação para garantir sua durabilidade. Porém, devido à grande variedade de minerais que podem servir de matéria-prima, sempre haverá diferenças nas propriedades desse material, o que torna necessário um estudo prévio de seu comportamento. O conhecimento das características físicas, mecânicas e microestruturais 
propicia a predição de seu desempenho em componentes para construção civil. Características do material como a natureza da rocha, estado de alteração, estrutura, textura e presença de substâncias prejudiciais, precisam ser determinadas, para evitar falhas nos componentes construtivos. Porém, não se percebe, com a frequência desejável, a realização de testes prévios com esses materiais, por parte dos produtores.

No concreto, os agregados são componentes granulares de origem mineral e participam com grãos miúdos e graúdos, de forma combinada e contínua. Os agregados influenciam nas propriedades do concreto em aspectos físicos (massa específica, textura), mecânicos (resistência, dureza) e aspectos químicos (reatividade, durabilidade), podendo conter elementos indesejáveis (material pulverulento, matéria orgânica etc.).

Os agregados ocupam aproximadamente três quartos do volume do concreto e, muitas vezes, são vistos como materiais inertes e de baixo valor monetário. Porém, (como citado anteriormente) suas propriedades influenciam no desempenho do concreto produzido, tornando os agregados componentes não inertes do concreto. Mesmo conhecendo as propriedades dos agregados, não é fácil definir um bom agregado para concreto. Já que, a depender da função estabelecida para o concreto, tanto um agregado com todas as propriedades satisfatórias, quanto um agregado aparentemente inferior podem fazer parte da produção de um bom concreto e, por estes motivos, tornam-se necessárias análises e testes de desempenho dos concretos para evidenciar a qualidade dos agregados na produção de concretos [8].

\section{MATERIAIS E MÉTODOS}

Utilizou-se cimento tipo CP II Z-32, com índice de finura de 1,70\%, medido segundo a norma NBR 11579 (ABNT, 2012) [9] e tempo de início pega de 2h20, medido segundo a norma NBR NM 65 (ABNT, 2003) [10]. A areia foi obtida do comércio local, do tipo areia de cava. Usou-se o aditivo superplastificante ADVA ${ }^{\circledR}$ 175. As britas estudadas foram obtidas por trituração, em triturador de mandíbulas. As rochas foram coletadas em duas jazidas, na área explorada pela Cooperativa dos Trabalhadores em Extração, Beneficiamento e Comercialização de Rochas do Município de Tomar do Geru (COOPERPEDRAS). As britas das duas jazidas foram submetidas à análise petrográfica por microscopia, utilizando-se microscópios binoculares da marca Opton ${ }^{\circledR}$, modelo TNP 09. As composições minerais obtidas dessas análises são mostradas nas Tabelas 1 e 2.

Tabela 1 : Composição mineral das britas da jazida Cardoso 2 (504)

\begin{tabular}{cc}
\hline \hline Minerais & $\%$ \\
\hline Microclínio & 14,4 \\
\hline Plagioclásio & 65,6 \\
\hline Quartzo & 20 \\
\hline Biotita & 4,6 \\
\hline Minerais Opacos & $\operatorname{tr}$ \\
\hline Titanita & $\operatorname{tr}$ \\
\hline Clorita & $\operatorname{tr}$ \\
\hline Epídoto & $\operatorname{tr}$ \\
\hline Zircão & $\operatorname{tr}$ \\
\hline \hline
\end{tabular}


Tabela 2 : Composição mineral das britas da jazida Laje Grande (505)

\begin{tabular}{cc}
\hline \hline Minerais & $\%$ \\
\hline Microclínio & 3,2 \\
\hline Plagioclásio & 89,4 \\
\hline Quartzo & 7,3 \\
\hline Biotita & 5,8 \\
\hline Minerais Opacos & $\mathrm{Tr}$ \\
\hline Moscovita & $\mathrm{Tr}$ \\
\hline Apatita & $\mathrm{Tr}$ \\
\hline Epídoto & $\mathrm{Tr}$ \\
\hline Zircão & $\mathrm{Tr}$ \\
\hline \hline
\end{tabular}

Cada brita foi separada em duas faixas granulométricas (britas 0 e 1) e receberam denominação de acordo com a localização das jazidas (504 e 505). Adotou-se a terminologia GR-504 e GR-505. Foram produzidas duas misturas de concreto, com cada uma dessas britas, além da mistura de referência, produzida com uma brita comumente utilizada em concretos e obtida do comércio local. As britas foram caracterizadas fisicamente, no Laboratório de Materiais de Construção e Estruturas da UFS (Tabela 3).

Tabela 3 : Características físicas da areia e das britas utilizadas

\begin{tabular}{|c|c|c|c|}
\hline Agregados & Características & Resultados & Normalização \\
\hline \multirow[b]{2}{*}{ Areia } & Massa específica real $\left(\mathrm{g} / \mathrm{cm}^{3}\right)$ & 2,62 & NBR NM 52 [11] \\
\hline & $\begin{array}{l}\text { Diâmetro máximo (mm) } \\
\text { Módulo de finura }(\%)\end{array}$ & $\begin{array}{c}2,4 \\
2,43\end{array}$ & NBR NM 248 [12] \\
\hline \multirow[b]{2}{*}{ B0-REFER } & Massa específica real $\left(\mathrm{g} / \mathrm{cm}^{3}\right)$ & 2,65 & NBR NM 53 [13] \\
\hline & $\begin{array}{l}\text { Diâmetro máximo }(\mathrm{mm}) \\
\text { Módulo de finura }(\%)\end{array}$ & $\begin{array}{l}9,5 \\
5,73\end{array}$ & NBR NM 248 [12] \\
\hline \multirow[b]{2}{*}{ B1-REFER } & Massa específica real $\left(\mathrm{g} / \mathrm{cm}^{3}\right)$ & 2,72 & NBR NM 53 [13] \\
\hline & $\begin{array}{l}\text { Diâmetro máximo }(\mathrm{mm}) \\
\text { Módulo de finura }(\%)\end{array}$ & $\begin{array}{l}19,0 \\
6,64\end{array}$ & NBR NM 248 [12] \\
\hline \multirow[b]{2}{*}{ B0-504 } & Massa específica real $\left(\mathrm{g} / \mathrm{cm}^{3}\right)$ & 2,69 & NBR NM 53 [13] \\
\hline & $\begin{array}{l}\text { Diâmetro máximo (mm) } \\
\text { Módulo de finura }(\%)\end{array}$ & $\begin{array}{c}9,5 \\
4,22\end{array}$ & NBR NM 248 [12] \\
\hline \multirow[t]{2}{*}{ B1-504 } & Massa específica real $\left(\mathrm{g} / \mathrm{cm}^{3}\right)$ & 2,69 & NBR NM 53 [13] \\
\hline & $\begin{array}{c}\text { Diâmetro máximo }(\mathrm{mm}) \\
\text { Módulo de finura }(\%)\end{array}$ & $\begin{array}{l}19,0 \\
6,97\end{array}$ & NBR NM 248 [12] \\
\hline \multirow[t]{2}{*}{ B0-505 } & Massa específica real $\left(\mathrm{g} / \mathrm{cm}^{3}\right)$ & 2,70 & NBR NM 53 [13] \\
\hline & $\begin{array}{l}\text { Diâmetro máximo }(\mathrm{mm}) \\
\text { Módulo de finura }(\%)\end{array}$ & $\begin{array}{c}9,5 \\
5,29\end{array}$ & NBR NM 248 [12] \\
\hline \multirow[t]{2}{*}{ B1-505 } & Massa específica real $\left(\mathrm{g} / \mathrm{cm}^{3}\right)$ & 2,70 & NBR NM 53 [13] \\
\hline & $\begin{array}{l}\text { Diâmetro máximo }(\mathrm{mm}) \\
\text { Módulo de finura }(\%)\end{array}$ & $\begin{array}{l}9,5 \\
6,97\end{array}$ & NBR NM 248 [12] \\
\hline
\end{tabular}

A dosagem dos concretos seguiu o método do American Concrete Institute (ACI) adaptado pela Associação Brasileira de Cimento Portland (ABCP) [14]. A dosagem dos concretos foi determinada a partir da resistência característica à compressão $\left(\mathrm{f}_{\mathrm{ck}}\right)$, de $30 \mathrm{MPa}$ e abatimento do tronco de cone de $70 \mathrm{~mm} \pm 10 \mathrm{~mm}$, medidos segundo a norma NBR NM 67 (ABNT, 1998) [15]. O traço em massa, igual para as três misturas, resultou na proporção 1,00:1,55:2,40, com $30 \%$ de brita 0 e $70 \%$ de brita 1 e relação água/cimento de 0,45 . Foram moldados 14 corpos de prova, com $100 \mathrm{~mm}$ de diâmetro e $200 \mathrm{~mm}$ de altura, para cada mistura, sendo seis para ensaios de resistência à compressão axial, de acordo com a norma NBR 5739 (ABNT, 2007) [16], seis 
para resistência à tração por compressão diametral, NBR 7222 (ABNT, 2011) [17], e dois para determinação do módulo de elasticidade à compressão, NBR 8522 (ABNT, 2008) [18]. Os corpos de prova foram desmoldados com 24 horas de idade e foram curados imersos em água por 28 dias. A moldagem e cura dos corpos de prova seguiram a norma NBR 5738 (ABNT, 2003) [19]. Após esse período, os corpos de prova tiveram seus topos retificados e foram submetidos aos ensaios mecânicos, utilizando-se a máquina universal de ensaios DL 20000, com prensa de compressão PCE 100, marca EMIC.

\section{RESULTADOS E DISCUSSÃO}

A análise petrográfica permitiu que as rochas de Tomar do Geru fossem classificadas como metamórficas, denominadas gnaisses migmatíticos. Os trabalhadores da COOPERPEDRAS sempre foram conhecidos como "graniteiros de Tomar do Geru", por se julgar que as rochas eram de granito, quando, na verdade, são de gnaisse.

Porém, pela baixa potência do microscópio usado no método de análise praticado, não foi possível a quantificação e nem identificação de minerais reativos. Não foi possível distinguir a sílica amorfa da cristalina. Assim, não se pode afirmar que as britas das duas jazidas analisadas são potencialmente reativas, ou seja, que podem propiciar, ou não, a ocorrência de reação álcaliagregado.

Os resultados dos ensaios de resistência à compressão dos concretos estudados estão mostrados individualmente nas Figuras 2, 3 e 4, e foram sintetizados na Tabela 4.

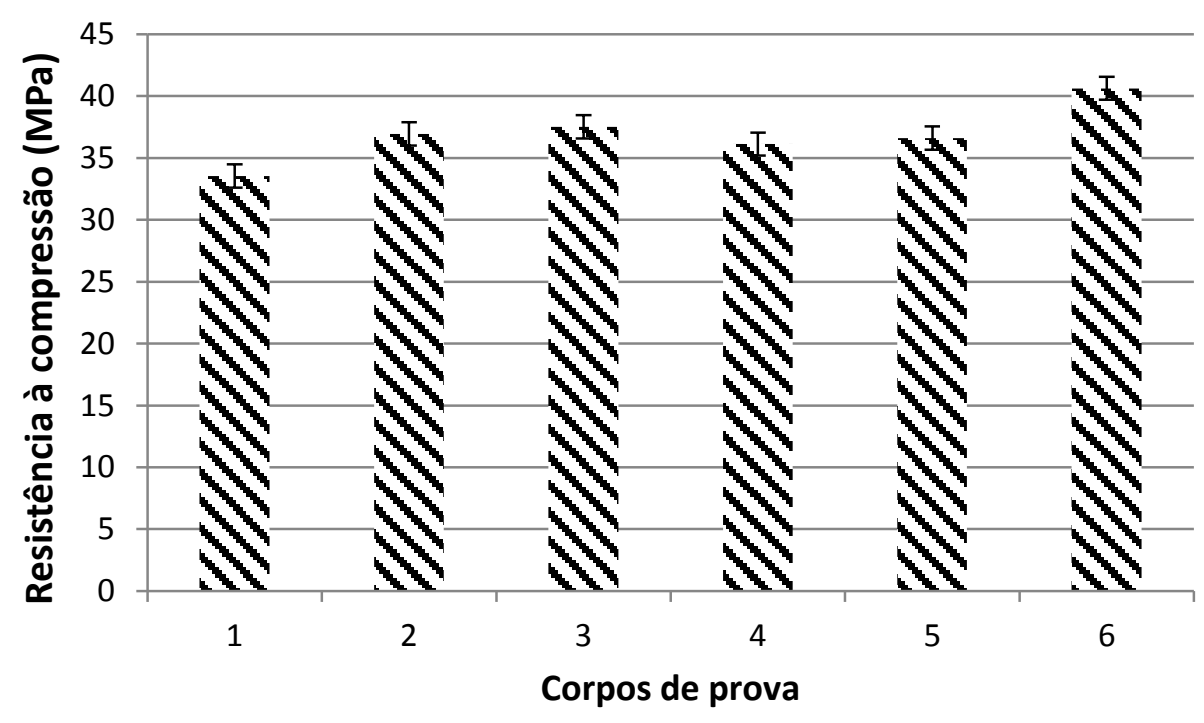

Figura 2 : Resultados individuais dos corpos de prova do concreto de Referência 


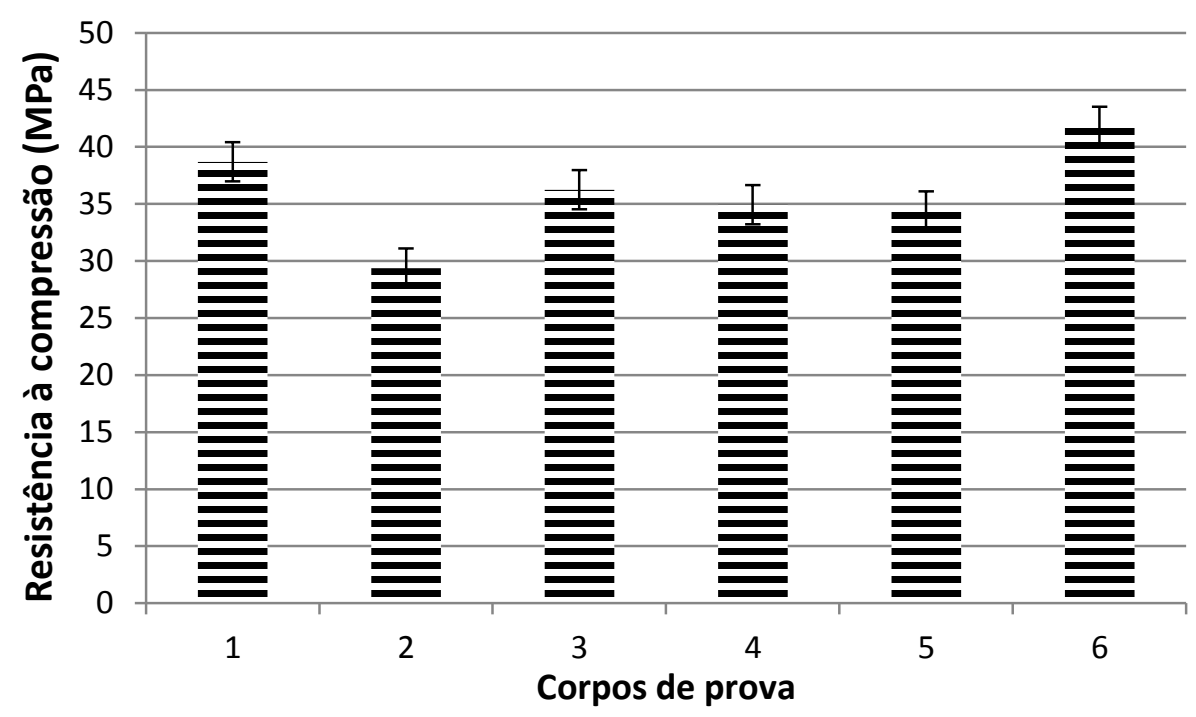

Figura 3 : Resultados individuais dos corpos de prova do concreto GR-504

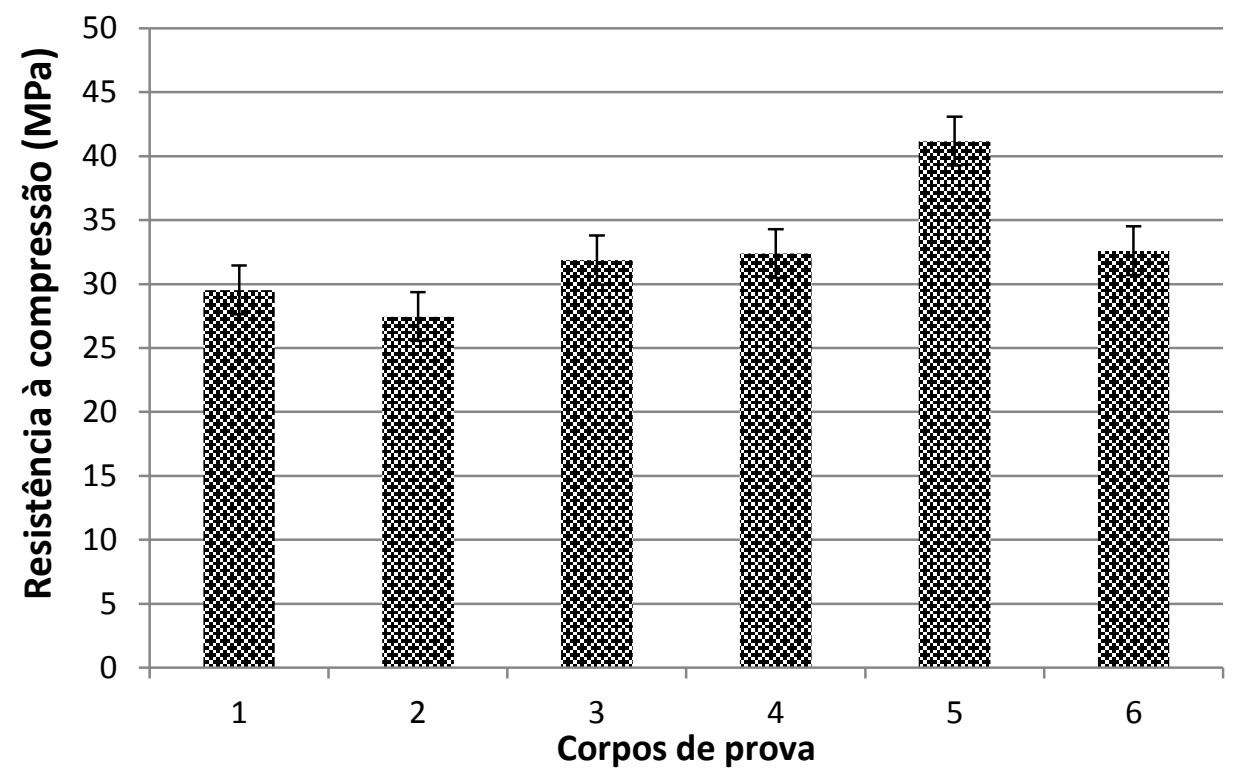

Figura 4 : Resultados individuais dos corpos de prova do concreto GR-505

\begin{tabular}{ccc}
\multicolumn{3}{c}{ Tabela 4:Resultados dos ensaios de compressão axial } \\
\hline \multirow{2}{*}{ Concreto } & \multicolumn{2}{c}{ Parâmetros dos ensaios de compressão } \\
\cline { 2 - 3 } & Média (MPa) & Coeficiente de variação (\%) \\
\hline REFER & 36,89 & 6,21 \\
GR-504 & 35,91 & 11,70 \\
GR-505 & 32,51 & 14,42 \\
\hline
\end{tabular}

Os valores medidos de resistência à compressão dos concretos superaram o valor previsto na dosagem dos concretos, cujo $\mathrm{f}_{\mathrm{ck}}$ foi de $30 \mathrm{MPa}$. Esses valores ficaram muito próximos entre si, mostrando que as britas das jazidas do município de Tomar do Geru estão adequadas, em termos de resistência mecânica, para serem usadas em concretos estruturais. $\mathrm{O}$ concreto com a brita GR-504 apresentou redução pouco significativa, de 2,6\%, na resistência à compressão, comparado com o concreto de referência. Para o concreto com a brita GR-505, a redução foi de $11,9 \%$, podendo esse concreto ser considerado como adequado, em termos de resistência mecânica. 
Os resultados dos ensaios de módulo de elasticidade dos concretos produzidos com as britas de referência, GR-504 e GR-505 estão mostrados na Tabela 5.

Tabela 5 : Valores de módulo de elasticidade dos concretos estudados

\begin{tabular}{lc}
\hline Concreto & Módulo de elasticidade (GPa) \\
\hline REFER & 33,21 \\
GR-504 & 30,12 \\
GR-505 & 28,29 \\
\hline
\end{tabular}

Os valores medidos, para essa propriedade, para os concretos estudados, estão compatíveis com aqueles esperados para um concreto estrutural. Pode-se perceber que houve decréscimo do módulo de elasticidade do concreto, com a utilização das britas investigadas. Para o concreto com brita GR-504, o módulo teve redução de 9,3\%, em relação ao módulo do concreto de referência. Para o concreto com a brita GR-505, essa redução foi de 14,8\%. Essas reduções acompanham aquelas observadas para as medidas de resistência à compressão, pois concretos com maiores resistências à compressão deformam-se menos, resultando em maiores módulos de elasticidade. A norma NBR 6118 (ABNT, 2014) [20] estabelece que, na impossibilidade de se fazer ensaios, o módulo de elasticidade tangente inicial pode ser determinado pela Equação 01, para concretos com $\mathrm{f}_{\mathrm{ck}}$ entre $20 \mathrm{MPa}$ e $50 \mathrm{MPa}$. $\mathrm{O}$ valor de $\alpha_{\mathrm{E}}$ varia com a composição do mineral do agregado, sendo igual a 1,0 para granito e gnaisse. Assim, o valor do módulo de elasticidade dos concretos estudados poderia ser presumido como igual a 30,67 GPa, segundo a citada norma. O menor valor encontrado para o módulo, para o concreto com brita GR-505, está apenas 8\% abaixo dessa predição.

$$
E_{c i}=\propto_{E} \cdot 5600 \cdot \sqrt{f_{c k}}
$$

Os resultados dos ensaios de resistência à tração por compressão diametral dos concretos estudados estão mostrados nas Figuras 5, 6 e 7, e foram resumidos na Tabela 6.

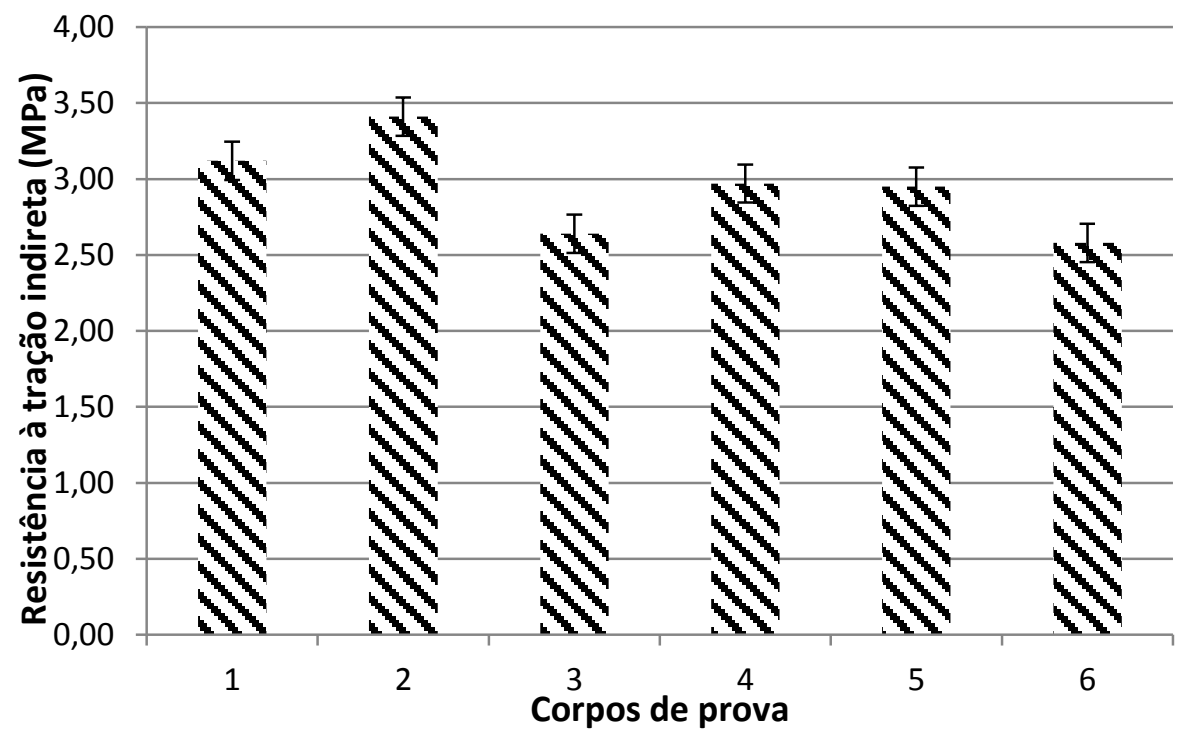

Figura 5 : Resultados individuais dos corpos de prova do concreto de Referência 


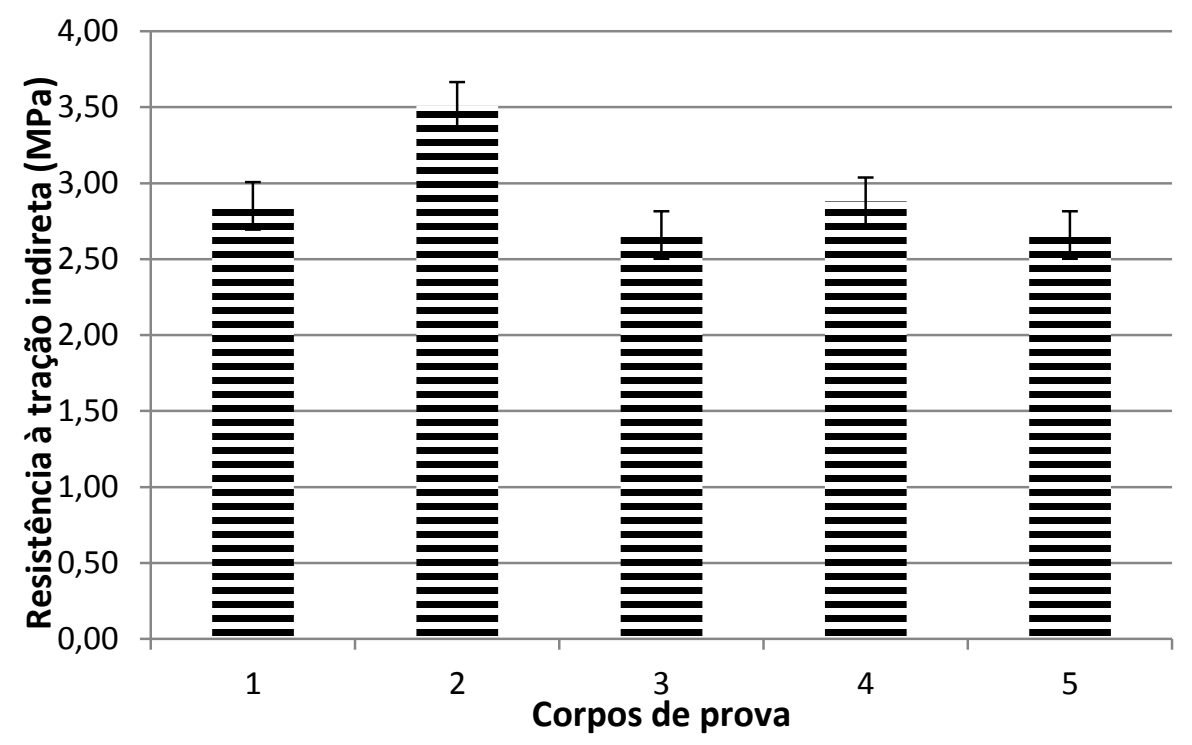

Figura 6 : Resultados individuais dos corpos de prova do concreto GR-504

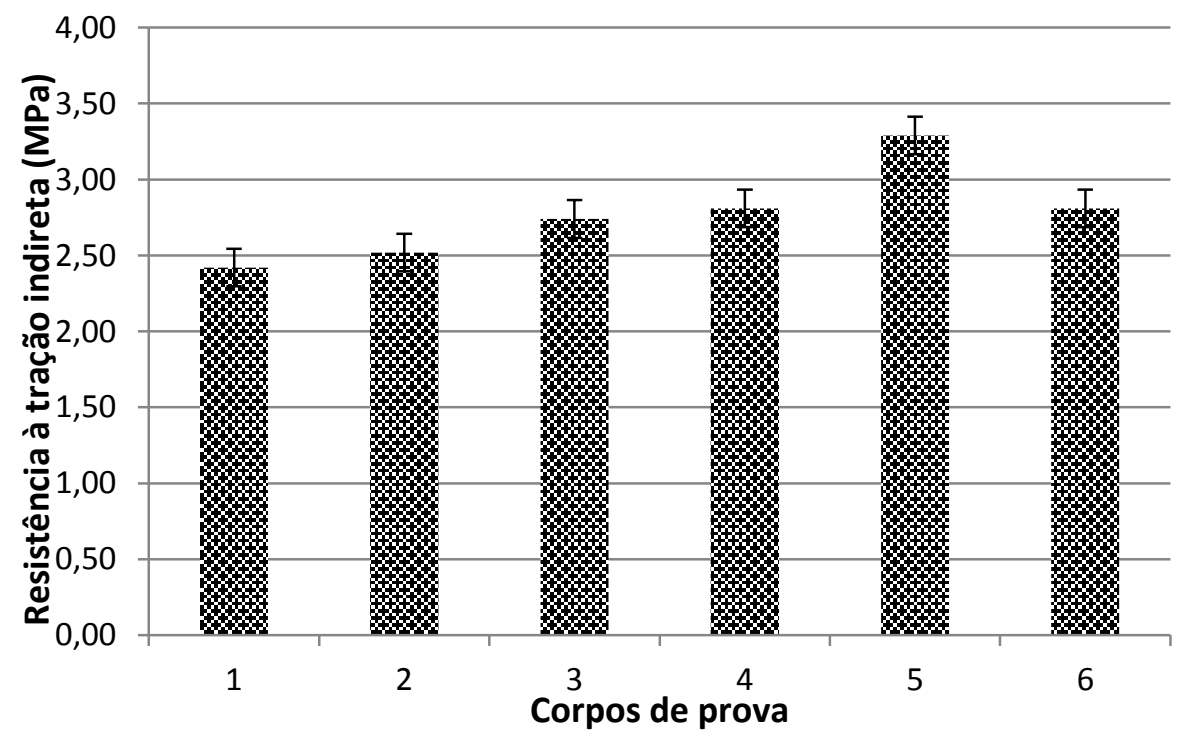

Figura 7 : Resultados individuais dos corpos de prova do concreto GR-505

Tabela 6 : Resultados dos ensaios de tração por compressão diametral

\begin{tabular}{|c|c|c|}
\hline \multirow{2}{*}{ Concreto } & \multicolumn{2}{|c|}{ Parâmetros dos ensaios de tração por compressão diametral } \\
\hline & Média (MPa) & Coeficiente de variação $(\%)$ \\
\hline REFER & 2,95 & 10,45 \\
\hline GR-504 & 2,91 & 12,01 \\
\hline GR-505 & 2,77 & 10,96 \\
\hline
\end{tabular}

Submetidos à tração por compressão diametral, os concretos apresentaram valores bastante próximos para a tensão de ruptura e valores médios compatíveis com os de concretos estruturais. Em relação ao concreto de referência, o concreto com britas GR-504 obteve resistência à tração somente 1,4\% inferior, enquanto o concreto com britas GR-505 apresentou redução de $6,1 \%$. Essas reduções não muito acentuadas dos valores obtidos para resistência à tração indireta, para os concretos com as britas de Geru em relação ao concreto de referência, eram esperadas, devido à pequena redução, também apresentada, nos valores de resistência à compressão. De acordo com Mehta e Monteiro (2008) [21], a relação entre os valores de resistência à tração e os de resistência à compressão em concretos fica em torno de 7 a $10 \%$. Os 
valores obtidos para os concretos com britas das jazidas estudadas encontram-se inseridos nesse intervalo.

\section{CONCLUSÃO}

As britas das jazidas do município de Tomar do Geru, comparadas às britas obtidas do comércio local, não comprometeram a função estrutural dos concretos produzidos. Nos ensaios de resistência à compressão, o concreto produzido com as britas GR-504 e GR-505 apresentaram redução de resistência de 2,6\% e 11,9\%, respectivamente, em relação à mistura de referência. Apesar dessa redução, ambos os concretos atingiram resultados acima do valor especificado de dosagem, que foi de $30 \mathrm{MPa}$. Nos ensaios de módulo de elasticidade, foi percebido que os concretos com britas GR-504 e GR-505 apresentaram redução dessa propriedade de 9,3\% e $14,8 \%$, respectivamente. Foi verificado que os concretos estudados tiveram módulos de elasticidade compatíveis com os utilizados em concretos estruturais. Sob tração por compressão diametral, os concretos comparados apresentaram valores bem próximos entre si. Da mesma forma que nos ensaios de determinação da resistência à compressão, os concretos produzidos com as britas GR-504 e GR-505 apresentaram redução de 1,4\% e 6,1\%, respectivamente, mostrando coerência com os resultados da compressão e módulo de elasticidade. Assim, sob o ponto de vista de desempenho mecânico, é possível afirmar que as britas das jazidas analisadas de Tomar do Geru são adequadas para a produção de concretos com funções estruturais. A análise petrográfica por microscopia classificou e caracterizou a rocha de estudo. Não foi possível chegar à conclusão quanto à potencialidade de reações deletérias das britas estudadas.

\section{REFERÊNCIAS}

1. IBGE. Instituto Brasileiro de Geografia e Estatística. Cidades. [acesso em jun 2014]. Disponível em: http://cidades.ibge.gov.br/xtras/perfil.php?lang=\&codmun=280750\&search=sergipe|tomar-do-geru.

2. MME. Ministério de Minas e Energia. Diagnóstico do setor mineral do estado de Sergipe. Brasília, DF, 2009.

3. Ferreira GE, Oliveira BRG. Mercado de agregados no Brasil. In: Almeida SLM, Luz AD(org.). Manual de agregados para a construção civil. Rio de Janeiro: CETEM, 2009, p. 3-27.

4. Bitar OY. Urbanização, agregados minerais e sustentabilidade. São Paulo: IPT - Instituto de Pesquisas Tecnológicas do Estado de São Paulo, 2008.

5. Valverde FM. Agregados para a Construção Civil. Balanço Mineral Brasileiro, 2001. DNPM, 2001.

6. Bacci DLC, Landim PMB, Eston SM. Aspectos e impactos ambientais de pedreira em área urbana. Rem: Rev. Esc. Minas. 2006 Mar;59(1):47-8.

7. Campos EE, Frazão EB,Calaes, GD, HerrmannH. Agregados para a construção civil no Brasil: Contribuições para formulação de políticas públicas.Ver. Inst. Geol. 2013 Dez;34(2):69-17.

8. Neville A M, Brooks JJ.Tecnologia do concreto. Porto Alegre: Bookman, 2013.

9. ABNT. Associação Brasileira de Normas Técnicas. NBR 11579 - Determinação do índice de finura por meio da peneira $75 \mu \mathrm{m}$ (n $\left.\mathrm{n}^{\mathrm{o}} 200\right)$. Rio de Janeiro, 2012.

10. ABNT. Associação Brasileira de Normas Técnicas. NBR NM 65 - Cimento Portland - Determinação do tempo de pega. Rio de Janeiro, 2003.

11. ABNT. Associação Brasileira de Normas Técnicas. NBR NM 52 - Agregado miúdo - Determinação da massa específica e massa específica aparente. Rio de Janeiro: ABNT, 2009.

12. ABNT. Associação Brasileira de Normas Técnicas. NBR NM 248 - agregados - Determinação da composição granulométrica. Rio de Janeiro: ABNT, 2003.

13. ABNT. Associação Brasileira de Normas Técnicas. NBR NM 53 - Agregado graúdo - Determinação da massa específica, massa especifica aparente e absorção de água. Rio de Janeiro, 2009.

14. Rodrigues PPF. ET-67 Parâmetros de dosagem do concreto, 2nd ed. São Paulo: ABCP, 1995.

15. ABNT. Associação Brasileira de Normas Técnicas. NBR NM 67 - Concreto - Determinação da consistência pelo abatimento do tronco de cone. Rio de Janeiro, 1998.

16. ABNT. Associação Brasileira de Normas Técnicas. NBR 5739 - Concreto - Ensaios de compressão de corpos-de-prova cilíndricos. Rio de Janeiro, 2007. 
17. ABNT. Associação Brasileira de Normas Técnicas. NBR 7222 - Concreto e argamassa Determinação da resistência à tração por compressão diametral de corpos de prova cilíndricos.Rio de Janeiro, 2011.

18. ABNT. Associação Brasileira de Normas Técnicas. NBR 8522 - Concreto - Determinação do módulo estático de elasticidade a compressão. Rio de Janeiro, 2008.

19. ABNT. Associação Brasileira de Normas Técnicas.NBR 5738 - Concreto - Procedimento para moldagem e cura dos corpos-de-prova. Rio de Janeiro: ABNT, 2003.

20. ABNT. Associação Brasileira de Normas Técnicas. NBR 6118 - Projeto de estruturas de concreto Procedimento.Rio de Janeiro, 2014..

21. Mehta PK, Monteiro PJM. Concreto. Microestrutura, propriedades e materiais.Hasparyk NP, HeleneP, PaulonVA. (rev. e coord.). São Paulo: IBRACON, 2008. 